\title{
Contraceptive Method Choices Among Women In Oman: A Multilevel Analysis
}

\author{
Moza Said Al-balushi, M. S. Ahmed, M. Mazharul Islam and Md Hasinur Rahaman Khan ${ }^{1}$
}

\begin{abstract}
Contraception is not commonly used by Omani women because of socio-cultural traditions, religious beliefs and poor knowledge but among the users modern contraceptive methods are more popular than traditional methods. Multilevel analysis is conducted to investigate associations between individual and religion level characteristics and different type of contraceptive method and to obtain a better understanding of the factors associated with contraceptive method choices used by 15-49 years women in Oman using Oman National Reproductive Health Survey data. The results confirm the importance of individual's own characteristics have enduring effects on contraceptive method choices and it is found that for a given individual, contraceptive method choice varies across women's age, education level and their number of living children. We have found considerable differences in the results of the estimates between single and multilevel approaches.
\end{abstract}

Keywords: Contraceptive methods, Multilevel, Multinomial logistic regression, Oman, Oman National Reproductive Health Survey.

${ }^{1}$ The corresponding author 


\section{Introduction}

The National Center for Statistics and Information (NCSI) estimates the total population of the Sultanate of Oman to be 3.6 million (including 1.5 million expatriates; NCSI, 2013). About $13.9 \%$ and $33.7 \%$ of the population are under-5 years and under-15 years respectively with only $6 \%$ aged about 60 years and above. About $27.1 \%$ of the Omani population is female in the reproductive age group (15-49) who constitute nearly $55.2 \%$ of all females. The 2008 ONRHS has showed that the singulate mean age at first marriage is 29.1 years for males and 26.8 years for females. The rise of the singulate mean age might be one of the factors responsible for the decline in fertility rate in Oman. The total fertility rate of Omani women was estimated from 1993 census data to be 6.9 and has declined to 3.56 according to 2003 census and became 3.7 in the year 2012. The crude birth rate was estimated to be 32.1 per 1000 Omani population during 2012. The rate showed a drop of $20.3 \%$ over the past nineteen years (40.3 in 1993). This is also accompanied by a decline in the crude death rate from 7.3 in 1993 to 3.2 per 1000 Omani population in 2012. This represented a $56.2 \%$ decline in the past twenty years.

Maternal and child health services were uniformly implemented nationally in August 1987. It had the objectives to provide comprehensive care to mothers and their babies, to promote their health, and to reduce morbidity and mortality in both. In the seventh five year plan (2006-2010) the domain of women health and the domain of child health further emphasizes improving the healthy reproductive attitudes in the community and the health care provided to women in the post reproductive age. To achieve its objectives, the program targeted to increase the antenatal care coverage and to provide good prenatal care by promoting early booking during the first trimester of pregnancy.

This had enabled early detection and appropriate management of risk pregnancies and also facilitated to match the delivery needs of the women to the proper health facility according to the degree of risk expected at delivery. The program also aimed to promote hospital deliveries for optimal perinatal and immediate post-natal care to mothers and their babies at 2 and 6 weeks as well as child care up to school age. Birth spacing services were initiated in October 1994 as an integrated part of the program of "maternal and child health care". The service objectives were to make the contraceptive options available to the couples to regulate their fertility and remain free of diseases and death associated with high fertility and raise healthy children. Records show that a total of 19,128 were registered in Birth Spacing clinics in 2012, of which more than 99\% were Omanis; this included 9096 re-acceptors.

For efficient and effective program implementation of enhancing women's health in Oman, a statistical analysis of the determinants for use of contraception is crucial in minimization the costs of implementation of program activities. Often times, many studies have used single multinomial logistic for similar studies and predictors derived from such studies do not always reflect the true national level predictors because of failure to factor in the levels of stratification present for national level estimates. Therefore, one of the main aims of this study is to establish the differences between the application of multilevel and the traditional multinomial logistic regression with a specific application on the determinants of contraceptive use in Oman. 
There is a limited number of past research work on contraceptive use using contraceptive data in Oman. Riyami et al. (2004) discussed women's autonorny, education and employment status and their association with contraceptive use. Moza et al. (2015) discussed the determinants that are associated with the contraceptive use among 15-49 years aged married women in Oman using national reproductive health survey data. In literature, there is a number of past research work on contraceptive use where multilevel logistic regression models were used. Khan \& Shaw (2011), Khan (2010), and Khan \& Shaw (2009) used 2004 Bangladesh demographic and health survey (BDHS) contraceptive binary data to compare between different estimations and investigation of the selected determinants of contraceptive use. Grilli \& Rampichini (2006) determine the factors which influence the way of acquisition of the skills of the graduates and to evaluate the degree programs on the basis of the adequacy of the skills they give to their graduates. A multilevel multinomial logit model for the response of interest is fitted simultaneously with a multilevel logit model for the selection mechanism. Conflitti (2011) identify individual and country factors that determine a positive or negative perception of the euro. He estimated a multilevel multinomial logistic model to analyze how the support of the euro is affected by individual features and country macroeconomic characteristics. For details about multilevel modeling for categorical data can be found in Agresti et al. (2000), Daniels \& Gatsonis (1997).

\section{Data and Variables}

The data used in this study obtained from the 2008 Oman National Reproductive Health Survey (ONRHS). The survey was tagged on to the World Health Survey in Oman (OWHS) conducted in 2008. Both the ONRHS and OWHS were implemented by the Ministry of Health of Oman. The details of OWHS can be found in the OWHS report (2008). The ONRHS used a sub-sample of 3,703 Omani households out of 5,464 households selected for the OWHS. The ONRHS considered ever-married Omani women of reproductive age of 15 to 49 years. Finally 4,560 women successfully interviewed. The survey data followed a multistage stratified cluster sampling design. Stratification was made based on two factors: level of urbanization (urban/rural) and geographical distribution. Administratively, Oman was divided into 10 regions at the time of survey. The survey covered all the 10 regions of Oman, dividing into 10 urban and 10 rural strata. Equal sample were selected from all strata, with increased sample from urban Muscat. Ten clusters were selected from each strata randomly. The 2003 population census 'Enumeration Areas' (EAs) were considered as clusters. There were total of 3167 EAs in the country. Each EA contained on average 110 households arranged in two or more enumeration blocks (EBs). Twenty four households were selected systematically from the each selected EA. The hierarchy for this study follows individuals as level-1, region as level-2.

The outcome variable is method of contraceptive use which has three categories modern, traditional and not using. The modern method includes Pill, JUD, Injection, Family sterilization, Male sterilization, Vaginal methods, Condom, and Foam/Jelly. The traditional method includes 
Periodic abstinence, Withdrawal, Prolonged breastfeeding, and other. The independent variables were selected on the basis of empirical findings and theoretical explanations. Background characteristics were selected for inclusion in the analysis based or on their significant in the previous studies of contraceptive behavior or on their hypothesis association with contraceptive choice. They can be grouped broadly into contextual factors (region, place of residence) demographic factors (age, number of children) and socio-economic factors (education, wealth quartile, and living arrangement).

\section{Methodology}

Given that the dependent variable, method of contraceptive use, takes the form of an unordered categorical response variable, we chose to use multinomial logistic regression approach. Suppose that $y_{i}$ is the unordered categorical response for individual $i$, and that the response variable $t$ categories. We denote the probability of being in category $k$ by $\pi_{i(k)}=\operatorname{Pr}\left(y_{i}=k\right)$. Response category not using is taken as the reference category. A set of $t-1$ equations was then estimated, contrasting each of the remaining response categories with the chosen reference category. Suppose that the last category is taken as the reference, then, for a single explanatory variable $x$, a multinomial logistic regression model with logit link is written as

$$
\log \left(\frac{\pi_{i(k)}}{\pi_{i(t)}}\right)=\beta_{0(k)}+\beta_{1(k)} x_{i}, k=1, \ldots, t-1 .
$$

A separate intercept and slope parameter was estimated for each contrast, as indicated by the $k$ subscripts, although it is possible to constrain some or all to be equal. In the model above, the same explanatory variable appears in each of the $t-1$ contrasts. Here the parameter $\beta_{1(k)}$ is interpreted as the additive effect of a 1-unit increase in $x$ on the log-odds of being in category $k$ rather than category $t$. Predicted probabilities $\pi_{i(k)}(k=1, \ldots, t)$ are derived from Eq. (1) as.

$$
\pi_{i(k)}=\frac{\exp \left(\beta_{0(k)}+\beta_{1(k)} x_{i}\right)}{1+\sum_{k=1}^{t-1} \exp \left(\beta_{0(k)}+\beta_{1(k)} x_{i}\right)} .
$$

The probability of being in the reference category $t$ is obtained by subtraction.

$$
\pi_{i(t)}=1-\sum_{k=1}^{t-1} \pi_{i(k)} .
$$

Model interoperation using odds ratios were considered in this study. Suppose the $y_{i j}$ is the categorical response for individual $i$ in region (i.e. district) $j$, and denote the probability of being 
in category $k$ by $\pi_{i j(k)}$. Equation (1) can be in the form of a two level random intercept multinomial logistic model as

$$
\log \left(\frac{\pi_{i j(k)}}{\pi_{i j(t)}}\right)=\beta_{0(k)}+\beta_{1(k)} x_{i j}+u_{j(k)}, \quad k=1, \ldots, l-1,
$$

where $u_{j(k)}$ is a district-level random effect, assumed to be normally distributed with mean 0 and variance $\Omega$. The random effects are contrast-specific, as indicated by the $k$ subscript, because different unobserved district-level factors may affect each contrast. Or, equivalently, the intradistrict correlation in contraceptive use may vary by type of method. However, the random effects may be correlated across contrasts. Correlated random effects would arise, for example, if there were unobserved district-level factors which affect the choice of more than one method of contraceptive type. We could compute the degree of likeness between units belonging to the same cluster using the intra-class correlation coefficient.

Parameter estimation was based on penalized quasi likelihood (PQL) method. After applying the quasi likelihood method, the model was estimated using iterative generalized least squares [Goldstein (2003), Khan \& Shaw (2011)]. Second-order PQL method has been used throughout the multi-level analyses since this method approximates well [Goldstein (2003), Khan \& Shaw (2011)]. The PQL estimation procedure is described here briefly under generalized linear model framework and its usual notations. The logit model or the generalized linear model is

$$
\log \left(\frac{\pi_{i j(k)}}{\pi_{i j(t)}}\right)=\eta_{i j}=x_{i j}^{T} \gamma+Z_{i j}^{T} u_{j},
$$

for level-1 unit $i$ nested within level-2 unit $j$. At level 1, we assume $y_{i j}$ conditionally distributed as multinomial, while the random effects vector $u_{j}$ is distributed as $N\left(0, \sigma_{u}^{2}\right)$ across the level-2 units. Under PQL, in the case of unordered categorical outcomes with logit link, we start with the level-1 model

$$
y_{i j}=\pi_{i j(k)}+e_{i j}
$$

where $\mathrm{E}\left(e_{i j}\right)=0$ and $\operatorname{Var}\left(e_{i j}\right)=\pi_{i j(k)}\left(1-\pi_{i j(k)}\right)$. This is a nonlinear model which we linearize by means of the first-order Taylor expansion. Suppose at iteration s, we have

$$
\pi_{i j(k)} \approx \pi_{i j(k)}^{(s)}+\frac{d \pi_{i j(k)}}{d \eta_{i j}}\left(\eta_{i j}-\eta_{i j}^{(s)}\right)
$$

and evaluate the derivative 


$$
\frac{d \pi_{i j(k)}}{d \eta_{i j}}=\pi_{i j(k)}\left(1-\pi_{i j(k)}\right)=\omega_{i j}
$$

at $\pi_{i j(k)}^{(s)}$. Substituting the linear approximation for $\pi_{i j(k)}$ in equation (5) yields

$$
y_{i j}=\pi_{i j(k)}^{(s)}+\omega_{i j}^{(s)}\left(\eta_{i j}-\eta_{i j}^{(s)}\right)+e_{i j} .
$$

Algebraically rearranging this equation produces

$$
\frac{y_{i j}-\pi_{i j(k)}^{(s)}}{\omega_{i j}^{(s)}}+\eta_{i j}^{(s)}=\eta_{i j}+\frac{e_{i j}}{\omega_{i j}^{(s)}} .
$$

This equation has the form of the familiar two-level hierarchical linear model

$$
y_{i j}^{*(s)}=x_{i j}^{T} \gamma+Z_{i j}^{T} u_{j}+\varepsilon_{i j}
$$

which gives a straight forward updating scheme. Here,

$$
y_{i j}^{*(s)}=\left(y_{i j}-\pi_{i j(k)}^{(s)}\right) / \omega_{i j}^{(s)}+\eta_{i j}^{(s)}, \varepsilon_{i j}=e_{i j} / \omega_{i j}^{(s)} \approx N\left(0, \omega_{i j}^{(s)-1}\right) \text { and } u_{j} \sim N(0, T) .
$$

The estimate of $\eta_{i j}^{(s)}$ can be written as below

$$
\eta_{i j}^{(s)}=x_{i j}^{T} \hat{\gamma}^{(s)}+Z_{i j}^{T} u_{j}^{*(s)}
$$

where $u_{j}^{*(s)}$ is the approximate posterior mode, i.e.

$$
u_{j}^{*(s)}=\left(Z_{j}^{T} W_{j}^{(s)} Z_{j}+T^{(s)-1}\right)^{-1} Z_{j}^{T} W_{j}^{(s)}\left(y_{j}^{*(s)}-x_{j} \hat{\gamma}^{(s)}\right)
$$

for $W_{j}^{(s)}=\operatorname{diag}\left\{\omega_{i j}^{(s)} \ldots \omega_{n_{j} j}^{(s)}\right\}$.

\section{Data Analysis}

Table 1 presents the percentage of married women who are currently using specific family planning method in Oman in 2008. Overall 28.9 percent of Omani married women are using 
contraceptives. The prevalence of modern method is 18.3 percent and 10.7 for traditional methods among married women. The modern contraceptive methods are relatively more prevalent than the traditional methods. Withdrawal $(6 \%)$ had the highest prevalence, which is followed by injection (4.4\%) and then the pills (4\%). Overall, the use of contraceptive methods among married women in Oman is still below the expected regional prevalence level.

Table 1. Currently Using Contraceptive Methods by the Married Women Aged 15-49 Years in

Oman

\begin{tabular}{|cc|}
\hline Contraceptive method & Percentage \\
\hline All methods & 28.9 \\
\hline Modern methods & 18.3 \\
Pills & 4.0 \\
IUD & 2.9 \\
Injection & 4.4 \\
Female sterilization & 3.9 \\
Male sterilization & 0.0 \\
Vaginal methods & 0.0 \\
Condom & 3.1 \\
Foam/Jelly & 0.0 \\
\hline Traditional methods & 10.7 \\
Periodic abstinence & 2.3 \\
Withdrawal & 6.0 \\
Prolonged breastfeeding & 1.9 \\
Other & 0.6 \\
\hline
\end{tabular}

Table 2 shows that women with (15-24) and (25-29) age-groups almost equally use modern and traditional methods, while women within (30-34), (35-39), (40-44) and (45-49) age-groups preferred modern methods to traditional methods and more than 75 percentage of the women in (15-24) and (45-49) age-groups did not use any contraceptive method. Women who used contraceptive methods and lived in urban and rural preferred modern methods, however more than 65 of them did not use contraceptive methods. 
Table 2. Percentage Distribution of Contraceptive Use Method by Married Women Aged 15-49 and Behavior Characteristics

\begin{tabular}{|c|c|c|c|}
\hline Variable & $\begin{array}{c}\text { Modern methods } \\
(\%)\end{array}$ & $\begin{array}{l}\text { Traditional } \\
\text { methods } \\
(\%)\end{array}$ & $\begin{array}{c}\text { Not using } \\
\text { contraceptive } \\
(\%)\end{array}$ \\
\hline \multicolumn{4}{|l|}{ Age of women } \\
\hline $15-24$ & 11.9 & 10.6 & 77.5 \\
\hline $25-29$ & 14.6 & 13.5 & 71.9 \\
\hline $30-34$ & 22.5 & 12.6 & 64.9 \\
\hline $35-39$ & 18.1 & 13.5 & 68.4 \\
\hline $40-44$ & 27.2 & 5.0 & 67.8 \\
\hline $45-49$ & 14.7 & 4.2 & 81.1 \\
\hline \multicolumn{4}{|l|}{ Place of residence } \\
\hline Urban & 19.8 & 10.3 & 69.9 \\
\hline Rural & 14.0 & 11.6 & 74.4 \\
\hline \multicolumn{4}{|l|}{ Region } \\
\hline Muscat & 26.3 & 11.2 & 62.5 \\
\hline Dhofar & 15.8 & 10.8 & 73.4 \\
\hline Al-Dakhila & 11.4 & 6.4 & 82.2 \\
\hline North Sharqiah & 10.7 & 8.4 & 80.8 \\
\hline South Sharqiah & 17.3 & 5.9 & 76.9 \\
\hline North Batina & 21.6 & 11.1 & 67.3 \\
\hline South Batina & 13.1 & 15.7 & 71.2 \\
\hline Al-Dhahirah & 16.8 & 14.4 & 68.8 \\
\hline Musandam & 39.5 & 5.3 & 55.3 \\
\hline Al-Wasta & 15.6 & 15.6 & 68.8 \\
\hline \multicolumn{4}{|l|}{ Women education } \\
\hline Illiterate & 16.6 & 2.7 & 80.7 \\
\hline Primary/ Literate & 18.9 & 9.4 & 71.7 \\
\hline Preparatory completed & 23.6 & 11.5 & 64.9 \\
\hline Secondary completed & 16.8 & 13.3 & 69.9 \\
\hline College/university & 17.2 & 17.9 & 64.9 \\
\hline \multicolumn{4}{|l|}{ Number of children } \\
\hline$(0-2)$ children & 9.7 & 12.0 & 78.2 \\
\hline (3-4) children & 20.6 & 12.4 & 67.0 \\
\hline (5-7) children & 25.0 & 13.2 & 61.8 \\
\hline $8+$ & 21.4 & 4.7 & 73.9 \\
\hline \multicolumn{4}{|l|}{ Economic status } \\
\hline Poor & 21.7 & 9.5 & 68.8 \\
\hline Lower middle & 15.1 & 11.5 & 73.3 \\
\hline Upper middle & 17.9 & 9.2 & 72.9 \\
\hline Rich & 19.0 & 11.5 & 69.5 \\
\hline \multicolumn{4}{|l|}{ Living arrangement } \\
\hline Nuclear family & 20.8 & 11.1 & 68.2 \\
\hline Extended family/Composite & 16.0 & 10.3 & 73.7 \\
\hline
\end{tabular}


Most of the women who used contraceptive methods preferred modern methods in all regions except in South Batina where they preferred the traditional method and in Al-Wasta the number of women who prefer modern method is equal to the number of women who prefer traditional women. All women with different levels of education preferred modern methods except women with College/University certificate. Women with one and more children who used contraceptives preferred modern methods except women with (0-2) children who preferred traditional methods. Women who belong to different economic status and used contraceptive methods preferred modern methods. Women with different living arrangements and used contraceptive methods preferred modern methods. The results also showed a significant relationship between the choice of contraceptive method and women age, region, women education, number of children, economic status, and living arrangement.

We implemented the single and multilevel multinomial logistic regression model for choices of contraceptive methods. Table 3 shows that women who belong to (15-24) were 2.948 times more likely to use modern contraceptive methods compared to women who belong to (45-49) for multilevel model while women who belong to (15-24) were 2.609 times more likely to use modern contraceptive methods compared to (45-49) for standard regression model (single level). Compared to those who lived in urban areas, women who lived in rural areas were 1.236 times as likely to use modern methods of contraception under multilevel and 1.229 times more likely to use modern contraception than no method under single level. Women who are more educated were found to more likely to use modern methods than those who had no education for multilevel model and similarly for the single level they were more likely to use modern methods than those who had no education. The odds of using modern method rather than no method at all are 1.543 times higher for women with college/university education than women who are had no education under multilevel. On the other hand, under standard the odds of using modern method rather than no method are 1.318 times higher for women with college/university education than women who had no education. Compared to women with no children, those with more than seven children were 4.250 times more likely to use modern methods of contraception under multilevel and only 3.367 times more likely to use modern contraception than no method at all under single level. The odds of using modern rather than no method are 1.172 times higher for women who belong to poor economic status than women who belong to rich economic status under multilevel and almost similar odds ratio is found under single level. Women with nuclear family were 1.015 more likely to use modern methods of contraceptive than women with extended family/ composite under multilevel level but under single level they were 1.022 more likely to use modern methods of contraceptive than women with extended family/ composite. 
Table 3. Estimated Coefficients (including standard errors) from Single and Multilevel Multinomial Logistic Regression Analysis (random coefficient model) for Modern Contraceptive Methods Used by the Married Women Aged 15-49 in Oman

\begin{tabular}{|c|c|c|c|c|c|c|c|}
\hline \multirow[t]{3}{*}{ Variable } & \multirow{2}{*}{\multicolumn{3}{|c|}{$\begin{array}{c}\text { Single level model } \\
\text { Modern methods vs. Not using }\end{array}$}} & \multirow{2}{*}{\multicolumn{3}{|c|}{$\begin{array}{c}\text { Multilevel model } \\
\text { Modern methods vs. Not using }\end{array}$}} & \multirow{3}{*}{$\begin{array}{l}\text { Over/Under } \\
\text { Estimation } \\
\end{array}$} \\
\hline & & & & & & & \\
\hline & $\widehat{\beta}$ & $\begin{array}{c}\text { P- } \\
\text { value }\end{array}$ & $\begin{array}{l}\text { Odds } \\
\text { Ratio }\end{array}$ & $\widehat{\beta}$ & $\begin{array}{c}\text { P- } \\
\text { value }\end{array}$ & $\begin{array}{l}\text { Odds } \\
\text { Ratio }\end{array}$ & \\
\hline Intercept & $-2.80(0.27)$ & 0.000 & & $-3.161(0.316)$ & 0.000 & 0.042 & $8 \%$ \\
\hline \multicolumn{8}{|l|}{ Age of women* } \\
\hline $15-24$ & $0.96(0.26)$ & 0.000 & 2.609 & $1.081(0.268)$ & 0.001 & 2.948 & $-11 \%$ \\
\hline $25-29$ & $0.63(0.22)$ & 0.005 & 1.875 & $0.734(0.231)$ & 0.000 & 2.083 & $-14 \%$ \\
\hline $30-34$ & $0.52(0.21)$ & 0.011 & 1.682 & $0.613(0.210)$ & 0.000 & 1.846 & $-15 \%$ \\
\hline $35-39$ & $0.28(0.18)$ & 0.124 & 1.326 & $0.346(0.187)$ & 0.038 & 1.413 & $-18 \%$ \\
\hline 40-44 & $0.32(0.18)$ & 0.077 & 1.375 & $0.366(0.184)$ & 0.038 & 1.442 & $-13 \%$ \\
\hline \multicolumn{8}{|l|}{$45-49(\mathrm{ref})$} \\
\hline \multicolumn{8}{|l|}{ Place of residence* } \\
\hline \multicolumn{8}{|l|}{ Rural (ref) } \\
\hline \multicolumn{8}{|l|}{ Women education* } \\
\hline \multicolumn{8}{|l|}{ Illiterate (ref) } \\
\hline Primary/Literate & $0.125(0.124)$ & 0.314 & 1.133 & $0.225(0.129)$ & 0.061 & 1.252 & $-44 \%$ \\
\hline Preparatory C & $0.333(0.176)$ & 0.058 & 1.395 & $0.402(0.182)$ & 0.008 & 1.495 & $-17 \%$ \\
\hline Secondary C & $0.065(0.196)$ & 0.701 & 1.067 & $0.196(0.179)$ & 0.364 & 1.217 & $-67 \%$ \\
\hline College/university & $0.276(0.225)$ & 0.220 & 1.318 & $0.434(0.228)$ & 0.097 & 1.543 & $-36 \%$ \\
\hline \multicolumn{8}{|l|}{ Number of children* } \\
\hline \multicolumn{8}{|l|}{ (0-2) child (ref) } \\
\hline (3-4) child & $0.931(0.160)$ & 0.000 & 2.538 & $0.952(0.162)$ & 0.000 & 2.591 & $-2 \%$ \\
\hline (5-7) child & $1.061(0.186)$ & 0.000 & 2.889 & $1.150(0.190)$ & 0.000 & 3.158 & $-8 \%$ \\
\hline $8+$ & $1.214(0.217)$ & 0.000 & 3.367 & $1.447(0.223)$ & 0.000 & 4.250 & $-16 \%$ \\
\hline \multicolumn{8}{|l|}{ Economic Status } \\
\hline Poor & $-0.16(0.131)$ & 0.223 & 1.173 & $0.159(0.134)$ & 0.132 & 1.172 & $0 \%$ \\
\hline Lower middle & $0.060(0.135)$ & 0.653 & 0.941 & $-0.036(0.137)$ & 0.104 & 0.965 & $67 \%$ \\
\hline $\begin{array}{l}\text { Upper middle } \\
\text { Rich (ref) }\end{array}$ & $0.064(0.133)$ & 0.628 & 1.066 & $0.086(0.135)$ & 0.065 & 1.090 & $-26 \%$ \\
\hline \multicolumn{8}{|l|}{ Living arrangement } \\
\hline $\begin{array}{c}\text { Nuclear family } \\
\text { Extended } \\
\text { family/Composite (ref) }\end{array}$ & $0.022(0.098)$ & .822 & 1.022 & $0.015(0.099)$ & 0.891 & 1.015 & $47 \%$ \\
\hline \multicolumn{8}{|l|}{ Random intercept } \\
\hline$\sigma_{u 0}^{2}=\operatorname{var}\left(u_{0 j}\right)$ & $0.224(0.111)$ & & & & & & \\
\hline$\sigma_{u 1}^{2}=\operatorname{var}\left(u_{1 j}\right)$ & $0.023(0.056)$ & & & & & & \\
\hline$\sigma_{u 01}=\operatorname{cov}\left(u_{0 j}, u_{1 j}\right)$ & $0.086(0.056)$ & & & & & & \\
\hline
\end{tabular}


The last column of Table 3 represents the percentage of under or over estimation of $\hat{\beta}$ coefficient by single level from multilevel modeling. It is found that the $\widehat{\beta}$ coefficient is under estimated for most of the variables except economic status and living arrangement. The $\hat{\beta}$ coefficients for the economic status group (lower middle) of single level model have been over estimated by almost $67 \%$ and the $\hat{\beta}$ coefficients for the living arrangement of single level model have been over estimated by almost $47 \%$. Table 3 also showed that woman age covariate for its all categories has been significant for multilevel model, but under the standard logistic model the age group (35-39) and (40-45) were not significant. On the other hand, place of residence was not significant under multilevel model but it was significant under standard logistic model. The results of fixed part of random coefficient model presented in Table 3 showed that the age of women for all groups were found to be significant determinates of variation in contraceptive traditional method in all regions with respect to the corresponding reference category except for the last category. Place of residence was found to be significant determinates of variation in contraceptive use for traditional method in all regions with respect to the corresponding reference categories except for standard logistic model, but was not significant for multilevel model. Women education and number of children were found to be significant determinates of variation in traditional contraceptive use in all regions with respect to the corresponding reference categories.

To assess multilevel and single-level models, we compare their corresponding parameter estimates. Table 4 showed by its last column that the $\widehat{\beta}$ coefficient under single level analysis corresponding to place of residence covariates has been over estimated about 12 percentage compared to that under multilevel estimation. Similarly, $\hat{\beta}$ coefficients for the women age group for (15-24) and (40-45) of single level model have been over estimated by almost $1 \%$ as compared to those under multilevel estimation. The $\widehat{\beta}$ coefficient under single level analysis corresponding to woman education covariate for its all categories has been overestimated with multilevel estimate. On the other hand the $\widehat{\beta}$ coefficients for the women age groups (25-29), (30-39) and (35-39) have been under estimated by almost $2 \%, 2 \%$ and $4 \%$ respectively. Similarly the $\hat{\beta}$ coefficients for number of children (5-7) and more than seven children group of single level model have been underestimated with multilevel estimate by almost $5 \%$ and $4 \%$ respectively. Table 3 and Table 4 showed also the estimates for the variances of intercept region $\sigma_{u 0}^{2}$ and $\sigma_{u 1}^{2}$ under modern and traditional methods. We found that there is significant difference between the regions. That is, there is unexplained region-level variation in the use of the modern contraceptive methods but there is no unexplained district-level variation in the use of the traditional contraceptive methods. 
Table 4. Estimated Coefficients (including standard errors) from Single and Multilevel Multinomial Logistic Regression Analysis (random coefficient model) for Traditional Contraceptive Methods Used by the Married Women Aged 15-49 in Oman 


\begin{tabular}{|c|c|c|c|c|c|c|c|}
\hline \multirow[t]{3}{*}{ Variable } & \multicolumn{3}{|c|}{ Single level model } & \multicolumn{3}{|c|}{ Multilevel model } & \multirow{3}{*}{$\begin{array}{l}\text { Over/ } \\
\text { Under } \\
\text { Estimatio } \\
\text { n }\end{array}$} \\
\hline & \multicolumn{3}{|c|}{$\begin{array}{c}\text { Traditional methods vs. Not } \\
\text { using }\end{array}$} & \multicolumn{3}{|c|}{$\begin{array}{c}\text { Traditional methods vs. Not } \\
\text { using }\end{array}$} & \\
\hline & $\widehat{\beta}$ & $\begin{array}{c}\text { P- } \\
\text { value }\end{array}$ & $\begin{array}{l}\text { Odds } \\
\text { Ratio }\end{array}$ & $\widehat{\beta}$ & $\begin{array}{c}\text { P- } \\
\text { value }\end{array}$ & $\begin{array}{l}\text { Odds } \\
\text { Ratio }\end{array}$ & \\
\hline Intercept & $-3.73(0.427)$ & 0.000 & & $-3.772(0.438)$ & 0.000 & 0.0230 & \\
\hline Age of the women* & & & & & & 1.0000 & \\
\hline $15-24$ & $0.644(0.402)$ & 0.109 & 1.904 & $0.635(0.408)$ & 0.013 & 1.8870 & $1 \%$ \\
\hline $25-29$ & $0.820(0.317)$ & 0.027 & 2.272 & $0.834(0.375)$ & 0.000 & 2.3025 & $-2 \%$ \\
\hline $30-34$ & $0.891(0.358)$ & 0.013 & 2.438 & $0.913(0.361)$ & 0.000 & 2.4918 & $-2 \%$ \\
\hline $35-39$ & $0.732(0.338)$ & 0.030 & 2.079 & $0.764(0.340)$ & 0.001 & 2.1468 & $-4 \%$ \\
\hline $40-44$ & $0.353(0.364)$ & 0.332 & 1.423 & $0.368(0.366)$ & 0.219 & 1.4448 & $1 \%$ \\
\hline \multicolumn{8}{|l|}{$45-49$ (ref) } \\
\hline \multicolumn{8}{|l|}{ Place of residence* } \\
\hline $\begin{array}{c}\text { Urban } \\
\text { Rural (ref) }\end{array}$ & Rural (ref) & 0.009 & .717 & $-0.298(0.130)$ & 0.065 & 0.7423 & $12 \%$ \\
\hline \multicolumn{8}{|l|}{ Women education* } \\
\hline \multicolumn{8}{|l|}{ Illiterate (ref) } \\
\hline Primary/Literate & $0.875(0.229)$ & 0.000 & 2.400 & $0.802(0.232)$ & 0.001 & 2.2300 & $9 \%$ \\
\hline Preparatory C & $1.167(0.281)$ & 0.000 & 3.212 & $1.120(0.285)$ & 0.000 & 3.0649 & $4 \%$ \\
\hline Secondary C & $1.232(0.262)$ & 0.000 & 3.428 & $1.215(0.270)$ & 0.000 & 3.3703 & $1 \%$ \\
\hline College/university & $1.961(0.287)$ & 0.000 & 7.105 & $1.956(0.291)$ & 0.000 & 7.0710 & $0 \%$ \\
\hline \multicolumn{8}{|l|}{ Number of children* } \\
\hline \multicolumn{8}{|l|}{ (0-2) child (ref) } \\
\hline (3-4) child & $0.417(0.179)$ & 0.020 & 1.517 & $0.435(0.178)$ & 0.002 & 1.5450 & $-4 \%$ \\
\hline (5-7) child & $0.227(0.229)$ & 0.322 & 1.255 & $0.216(0.229)$ & 0.266 & 1.2411 & $5 \%$ \\
\hline $8+$ & $0.294(0.292)$ & 0.314 & 1.342 & $0.283(0.292)$ & 0.340 & 1.3271 & $4 \%$ \\
\hline \multicolumn{8}{|l|}{ Economic status } \\
\hline Poor & $-0.04(0.178)$ & 0.840 & 0.965 & $-0.039(0.178)$ & 0.640 & 0.9618 & $-8 \%$ \\
\hline Lower middle & $0.033(0.173)$ & 0.850 & 1.033 & $0.028(0.174)$ & 0.967 & 1.0284 & $18 \%$ \\
\hline $\begin{array}{l}\text { Upper middle } \\
\text { Rich (ref) }\end{array}$ & $-0.08(0.178)$ & 0.675 & 0.928 & $-0.114(0.179)$ & 0.415 & 0.8923 & $-34 \%$ \\
\hline \multicolumn{8}{|l|}{ Living arrangement } \\
\hline $\begin{array}{c}\text { Nuclear family } \\
\text { Extended } \\
\text { family/Composite } \\
\text { (ref) }\end{array}$ & $0.019(0.133)$ & 0.887 & 1.019 & $.047(0.132)$ & 0.718 & 1.048 & $-60 \%$ \\
\hline \multicolumn{8}{|l|}{ Random intercept } \\
\hline$\sigma_{u 0}^{2}=\operatorname{var}\left(u_{0 j}\right)$ & $0.224(0.111)$ & & & & & & \\
\hline$\sigma_{u 1}^{2}=\operatorname{var}\left(u_{1 j}\right)$ & & & & $0.023(0.056)$ & & & \\
\hline$\sigma_{u 01}=\operatorname{cov}\left(u_{0 j}, u_{1 j}\right)$ & $0.086(0.056)$ & & & & & & \\
\hline
\end{tabular}




\section{Discussion and Conclusion}

This study finds that the decision to use and choose a particular method of contraception is a function of both individual and community characteristics. For the individual level, young women who are sexually active (e.g., age group 15-24) are showed that $11.9 \%$ use modern method (Pill, JUD, Injection, Family sterilization, Male sterilization, Vaginal methods, Condom, and Foam/Jelly) and $10.6 \%$ use traditional method (Periodic abstinence, Withdrawal, Prolonged breastfeeding, and other) this may propose a high risk of using of traditional method for this age. For all age group women prefer the modern method than traditional. As for example, 27.3\% of women even at age group (40-44) use modern method while only $5 \%$ use traditional method.

The 2008 Oman National Reproductive Health Survey data further shows that, the contraceptive use rate of modern and traditional methods in urban areas was $19.8 \%$ and $10.3 \%$ respectively. The results also show that for rural areas, the contraceptive use rate of modern and traditional methods were $14 \%$ and $11.6 \%$ respectively. These comparisons of contraception practices show that the women who live urban residence were more likely to use modern method than their rural counterparts. The results establish the most noticeable well known effect of women's education on contraceptive practice. The results find that consistently increased use of modern method and the practice of modern methods was more widespread among women with preparatory education. It may indicate that the higher educated women are more informed about various modern methods and their side effects, which influence them to use traditional methods. Region of women has significant positive effect on modern method preference. Number of living children is also a significant factor that affects the contraceptive method of choices. The women, as expected, with two and more living children are more likely to use contraceptive method (any) and therefore they prefer to use traditional method. Women with more than seven children prefer modern methods.

This study examines contraceptive method choice within a multilevel framework thereby allowing for an investigation of both socio-economic and individual characteristics. Multilevel logistic regression is implemented to investigate the effects of the explanatory variables on the contraceptive methods, controlling for hierarchical data structure and accounting for unexplained variance resulting from the sampling design. The multilevel model allows for correlation in probabilities of contraceptive methods used by women living in the same region. We have found that failure to account for such clustering effects leads either to underestimate or overestimate and incorrect inferences. An advantage of using multinomial model, rather than fitting separate binary logistic models for each type of method choice is that the effects of characteristics on the different choice of methods may be evaluated simultaneously and tested for equivalence. Further the model allows for covariance between the unobserved region influences on the different types of contraceptive method use. The significant region effect in the multilevel model suggests that there are unobservable region factors that influence choice of different types of contraceptive methods, especially the choice between modern versus not using and traditional versus not using. The intracommunity correlations suggest that 5.24 and 2.75 percent of the total unexplained variation in the choice of traditional and modern respectively versus not using methods is attributable to region 
factors and not included in the model. The results imply high homogeneity in the use of modern and traditional methods within region but are unable to shed light on what whether the factors behind that homogeneity are cultural or service related.

There are a number of conclusion and strategic implications that come from the multilevel analysis. It is essential to make a greater awareness among (15-49) aged ever-married women of the issues which are found to affect contraceptive use method significantly. May be all opportunities, namely, the school system and youth associates, can be considered to educate them about contraception methods so that women should pay attention on practicing and knowing of contraceptive methods more in their reproductive lives. Proper policy and planning is needed to adopt so that women living in rural areas increase their contraceptive use by using either modern or traditional method.

\section{References}

[1] Agresti A., Booth J. G., Hobart J. P., and Caffo, B. (2000). Random-effects modelling of categorical response data. Sociological Methodology, 30: 27-80.

[2] Annual Health Report (2012). DG of planning, Ministry of Health, Muscat, Sultanate of Oman Breslow, N.E and Clayton D.G. (1993). Approximate inference in generalized linear mixed models. J. Am. Statist. Assoc, 88: 9-25.

[3] Conflitti, C. (2011). Opinion surveys on the euro: a multilevel multinomial logistic analysis. ECARES No ECARES 2009-015, University Liber de Bruxelles.

[4] Daniels M. J. and Gatsonis C. (1997). Hierarchical polytomous regression models with applications to health services research. Statistics in Medicine, 16: 2311-2325.

[5] Goldstein, H. (1991). Nonlinear multilevel models with an application to discrete response data. Biometrika, 78: 45-51.

[6] Goldstein, H. (2003). Multilevel Statistical Models, 3rd edition, Oxford University Press.

[7] Goldstein, H. and Rasbash, J. (1996). Improved approximations for multilevel models with binary responses, Journal of the Royal Statistical Society, Series B, 159: 505-513.

[8] Grilli, L. and Rampichini, C. (2007). A multilevel multinomial logit model for the analysis of graduate's skills, Stat. Meth. \& Appl, 16: 381-393.

[9] Khan, M. H. R., and Shaw J. E. H. (2011). Multilevel Logistic regression analysis applied to binary contraceptive prevalence Data. Journal of Data Science, 9: 93-110.

[10]Khan, M. H. R. (2010). Multilevel Logistic Regression Analysis of Contraceptive Binary Data: Basics, Applications, Interpretation. VDM Verlag Dr. Muller, Germany.

[11]Khan, M. H. R. and Shaw J. E. H. (2009). Determinants of Contraceptive Use in Bangladesh: A Hierarchical Modeling Approach. The International Journal of Interdisciplinary Social Sciences, 4(4): 103-118. 
[12]Laird, N.M. (1987). Empirical Bayes methods for two-way contingency tables. Biometrika, 65: $581-590$.

[13]Moza S. A., Ahmed M. S., Islam M. M., and Khan M. H. R. (2015). Determinants of contraceptive use in Oman. Far East Journal of Theoretical Statistics, 50(1): 51-64.

[14] Oman World Health Survey Report (2008), Ministry of Health, Muscat, Sultanate of Oman.

[15]Riyami A. A., Afifi M., Mabry R. M. (2004). Women's autonomy, education and employment in Oman and their influence on contraceptive use. Reproductive Health Matters, 12(23): 144-154.

[16]The Statistical Year Book (2013). National Center for Statistical \& Information (NCSI), Sultanate of Oman.

Moza Said Al-balushi, M. S. Ahmed, M. Mazharul Islam

Sultan Qaboos University, Muscat, Oman

Md Hasinur Rahaman Khan1

hasinur@isrt.ac.bd

ISRT, University of Dhaka, Dhaka 1000, Bangladesh 